\title{
DO DIGITAL AO INTELIGENTE: OS TERRITÓRIOS DO CONHECIMENTO COMO ESTRATÉGIAS DE DESENVOLVIMENTO E/OU DE MARKETING TERRITORIAL ${ }^{1}$
}

Ricardo Fernandes ${ }^{2}$

Rui Gama ${ }^{3}$

\section{RESUMO}

\begin{abstract}
No contexto da nova economia e das novas tecnologias de informação e comunicação temos assistido, nos últimos anos, a um crescimento assinalável da pertinência das questões da gestão sustentável dos territórios nas suas diferentes dimensões. A cidade, considerando estas transformações (económicas, sociais, políticas e tecnológicas), renasce no quadro de um crescente colapso das barreiras espaciais, contribuindo para o aparecimento de um novo paradigma de desenvolvimento relacionado directamente com o incremento dos factores territoriais, essenciais no novo contexto de competitividade entre os territórios. Neste sentido, implementam-se novas formas de pensar a cidade com a integração das dimensões digital e inteligente e uma coabitação entre o espaço físico e o espaço virtual. Assim, o digital terá que ser encarado como suporte para o desenvolvimento de territórios inteligentes, vistos, por um lado, como "albergues" de conhecimento, desenvolvimento tecnológico, processos de aprendizagem e educação, transferência de tecnologia, procedimentos de inovação e meios inovadores e, por outro, como plataformas digitais de processamento, transferência e difusão de informação e conhecimento. Contudo, não devemos negar que, na actualidade, algumas das cidades utilizam estas estratégias para mera valorização da sua imagem e segundo uma "moda" que é imposta, sendo central uma discussão conceptual assente numa aproximação metodológica às novas formas de marketing territorial associadas à cidade do conhecimento e à sua necessidade de auto-promoção e valorização. A cidade inteligente, na sua relação com o marketing territorial estratégico e com o desenvolvimento territorial poderá ser a desejada base de cooperação e coordenação estratégica para a estruturação e prossecução do desenvolvimento sustentado e integrado dos territórios.
\end{abstract}

\footnotetext{
${ }^{1}$ Com apoio do projecto POCI/GEO/60243/2004 da Fundação para a Ciência e Tecnologia

${ }^{2}$ Bolseiro do Projecto "Cidades do Conhecimento e Competitividade: Características, Factores e Apostas estratégicas para o Desenvolvimento Regional. $\mathrm{O}$ caso das Cidades Médias da Região Centro de Portugal" (POCl/GEO/60243/2004), financiado pela Fundação para a Ciência e Tecnologia. ricardogeografia17@hotmail.com

${ }^{3}$ Instituto de Estudos Geográficos da Universidade de Coimbra e investigador responsável do POCl/GEO/60243/2004 - "Cidades do Conhecimento e Competitividade: Características, Factores e Apostas estratégicas para o Desenvolvimento Regional. O caso das Cidades Médias da Região Centro de Portugal", financiado pela Fundação para a Ciência e Tecnologia. rgama@fl.uc.pt
} 


\section{INTRODUÇÃO}

O desenvolvimento tecnológico que caracteriza as últimas décadas de progresso económico das sociedades ocidentais, transformou a cidade, outrora industrial, numa cidade da informação e do conhecimento. Fruto do desenvolvimento tecnológico e das redes de telecomunicações, a economia globalizou-se e o conceito de espaço alterou-se, as fronteiras deram lugar aos espaços económicos e a cidade à região. Os centros de decisão deixaram de estar fixos, tornando-se flexíveis para acompanharem os fluxos de desenvolvimento e deslocamento do sistema global da sociedade digital. Tal como afirma Amoeda (2003: 253), "deixamos de viver num ambiente determinado pela espacialidade dos lugares, passando a viver num ambiente determinado pela espacialidade dos fluxos de informação". Deste modo, a sociedade da informação e do conhecimento é encarada como uma sociedade que utiliza, predominantemente, recursos digitais, tecnologias da informação e comunicação para a troca de informação em formato digital e que suporta a interacção entre indivíduos com recurso a práticas e métodos em construção permanente. Segundo este pressuposto, as tecnologias da informação e da comunicação têm tido um papel preponderante no desenvolvimento dos territórios cuja base se centra numa economia global, digital e "inteligente".

$\mathrm{Na}$ dimensão "virtual", a emergência das cidades e regiões digitais como estratégias de desenvolvimento para a nova era da informação e do conhecimento surge directamente ligada ao crescimento exponencial da Internet e das infra-estruturas digitais. Contudo, a cidade digital não pode ser vista como uma estratégia isolada, estanque. O desenvolvimento dos territórios não poderá basear-se, apenas, na dimensão virtual destas estratégias, sendo fundamental reflectir acerca de uma nova abordagem que integra as dimensões social, política, económica e tecnológica de uma forma menos digital e mais territorial, em que as TIC's contribuam, mas não sejam as únicas bases estruturantes de desenvolvimento, papel este que deverá ser representado pelo território. Num outro patamar, temos que sublinhar que "o conhecimento é a nova marca para cidades e territórios" (SERRANO et al, 2005: 11). Neste sentido, a articulação estratégica entre os actores regionais deve valorizar e integrar este recurso nas dinâmicas da economia global, endogeneizando-o para criar valor.

O espaço urbano adquire um novo papel na economia e na sociedade actuais, reflexo intenso de uma nova economia baseada no poder que provém da posse de informação e conhecimento, encarados, genericamente, como resultado do acesso à informação e à Internet, principalmente observado nas cidades, "meios digitais" por excelência. As cidades e os territórios adquirem uma dimensão intangível, fruto do reconhecimento dos novos papéis dos indivíduos no processo de criação de valor. Os novos desafios económicos e sociais conduzem a novas políticas no que diz respeito à gestão territorial. Tendo como pressuposto o novo conceito de cidade, temos que encarar a tecnologia como responsável pela alteração física, económica e social dos espaços urbanos, isto é, a criação de espaços inteligentes. Partindo de uma reflexão teórica e conceptual, 
interessa-nos discutir o digital, como uma etapa para a criação de territórios do conhecimento e não como produto final. O território terá que ser considerado o suporte activo de todas as relações e o "ciberespaço", bem como as TIC's, serão complementares na formação de um sistema virtual de inovação, facilitador de todas as interacções (LÉVY, 2000). O fundir dos ambientes real e virtual de inovação cria uma nova dimensão que marca o arranque de um percurso para as cidades inteligentes e o seu "alastrar" para os territórios envolventes (regiões), através de novas ideias, novas políticas, e, principalmente, novas formas de abordar estas temáticas.

Toda esta problemática, focalizada na cidade inteligente e nos territórios do conhecimento, deve ser direccionada para os fundamentos das estratégias de desenvolvimento territorial. A "inteligência" dos espaços urbanos deverá ser encaminhada no sentido do desenvolvimento sustentado e pensado à escala global. Por outro lado, a presença de outro tipo de estratégias, ancoradas no marketing territorial, deverá apresentar-se como um complemento, sendo que verificamos, hoje em dia, a valorização excessiva destes processos, considerados de forma isolada e individualizada (muitas vezes desprovidos de uma base de planeamento estratégico), em detrimento daquilo que se afirma mais importante, o desenvolvimento (Figura 1). Neste sentido resta-nos questionar a potencialidade destas cidades e regiões inteligentes em relação ao equilíbrio que estabelecem, quer entre os domínios físico e virtual quer entre desenvolvimento e marketing, tendo em conta que na actualidade, cada vez mais, as vantagens competitivas dos territórios apenas poderão ser construídas apostando na valorização dos recursos imateriais, no conhecimento, no capital humano, na transferência de informação e na capacidade do território inteligente em mobilizar acções e decisões planeadas e sustentadas.

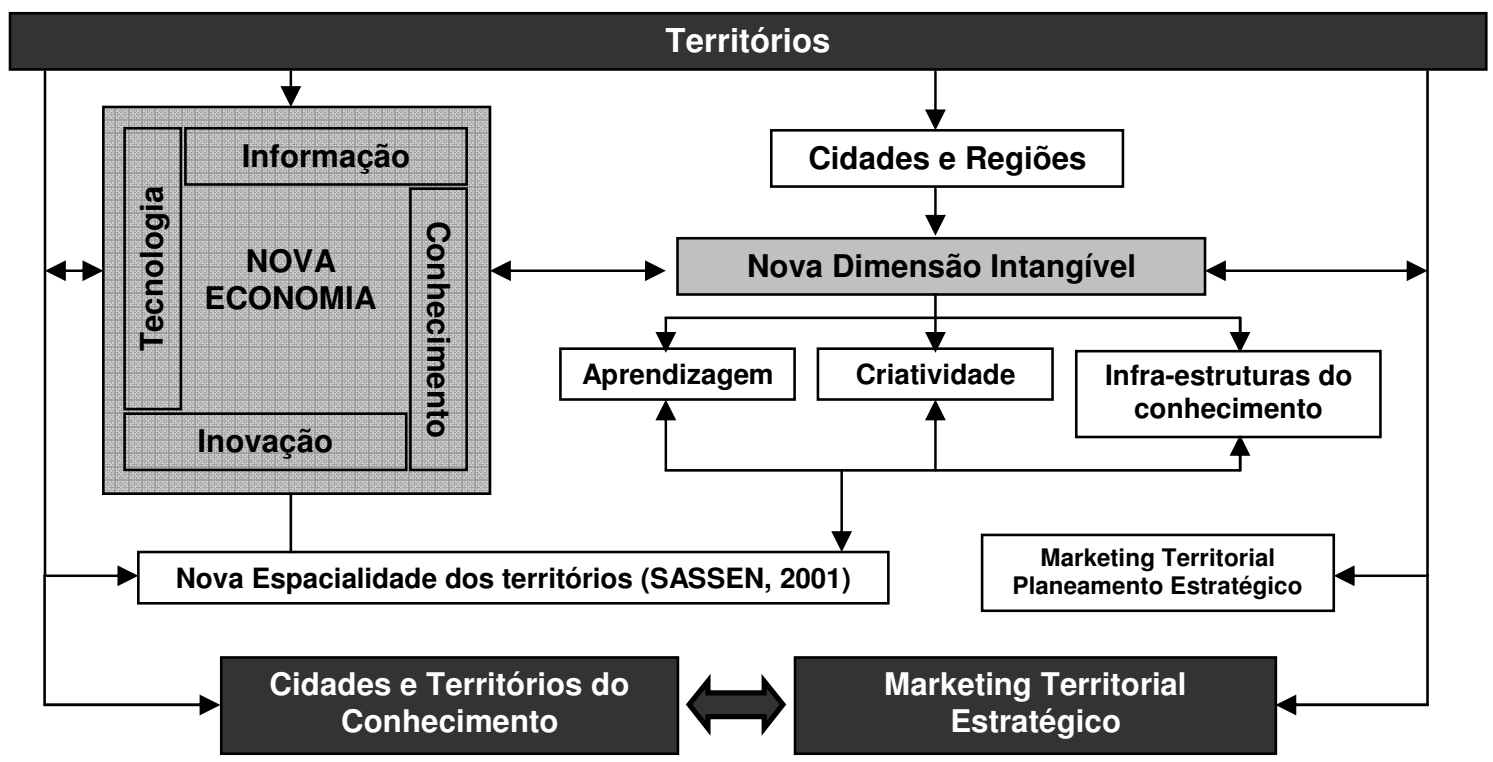

Figura 1. Esquema conceptual do artigo/temática apresentada 


\section{A NOVA ECONOMIA, A INTERNET E A EMERGÊNCIA DA CIDADE DIGITAL}

\subsection{A cidade no contexto da nova economia, da inovação e do conhecimento}

A revolução tecnológica que temos vindo a viver não se reflecte apenas com a centralidade da informação e do conhecimento. Segundo Castells (1999), esta é caracterizada pela aplicação destes conceitos na produção de conhecimento e dispositivos de processamento/comunicação da informação num "ciclo de realimentação" cumulativo entre a inovação e o seu uso. Deste modo, a informação e o conhecimento são factores distintivos nos processos de modernização, progresso e desenvolvimento das sociedades actuais e dos territórios. A economia foi-se alterando a par de uma diluição do conceito de espaço, surgindo, assim, novas formas de acção sócio-económica e uma "nova espacialidade dos territórios" (SASSEN, 2001). A nova economia digital e/ou do conhecimento aparece com uma orientação para os recursos digitais emergentes, centrando-se nas instituições, pessoas e na transferência informação e tecnologia, métodos, processos e na aprendizagem e conhecimento. No fundo, estes elementos são encarados na actualidade como veículos para a criação de riqueza assente no indivíduo, potenciando o seu poder científico e produtivo (GREGERSEN et al, 1997; CASTELLS, 2000; LUNDVALL, 2000; SERRANO et al, 2005).

A economia digital personifica as mudanças actuais na sociedade e na economia, sendo o trabalho intelectual e o conhecimento elementos centrais neste novo contexto e os novos serviços actividades emergentes na nova economia. Os dados, a informação, o conhecimento e a sua posse ou a possibilidade de os criar e dominar, assumem-se como novos meios de obter vantagens competitivas no actual contexto de mutações rápidas, concorrência e de globalização (GAMA, CAVALEIRO e FIGUEIREDO, 1999: 29). Assim, as características da nova economia digital podem integrar-se na possível participação descentralizada, coerente e globalizada dos actores, na centralidade da informação e conhecimento, nas competências dos processos, na criatividade, na aprendizagem e na inovação, como factores determinantes de competitividade. No fundo, a nova economia tem sido caracterizada pelo surgimento, desenvolvimento, adaptação e gestão de novas actividades económicas, novas formas de organização e pela importância da dimensão digital como veículo de tradução, gestão e utilização da informação e do conhecimento (GAMA, CAVALEIRO e FIGUEIREDO, 1999). Por outro lado, a conexão entre o espaço urbano, a tecnologia emergente e a nova forma de fazer economia levou a uma "metapolização" da cidade, em que as novas tecnologias de informação e comunicação revolucionaram e condicionaram as dinâmicas económicas, sociais, tecnológicas e organizacionais das cidades, tornando-as intimamente ligadas ao conhecimento e a um mundo assente em plataformas reais e virtuais.

Numa outra perspectiva, o conhecimento e o território desenvolvem uma relação complementar, onde o processo de desenvolvimento territorial apresenta ou deve apresentar, elementos como "a inovação e capacidades de adaptação e regulação" (COOKE, 2002), bem como conhecimento 
localizado, transferível e territorializado. A importância da aprendizagem colectiva explica a integração, neste contexto, da aprendizagem técnica, aprendizagem e conhecimento acumulados e contínuos, bem como o conhecimento e os processos de aprendizagem social (LUNDVALL, 2000). As cidades assumem-se como meios de inovação tecnológica, organizacional e empresarial por excelência, contribuindo assim para impulsionar estas áreas metropolitanas e de uma economia centrada na aprendizagem colectiva e no conhecimento, que neste contexto, é especificamente localizado. A cidade é o expoente máximo da nova economia pois tem a capacidade de manusear, trocar e combinar conhecimento recorrendo a diferentes redes, bem como dispõe de diferentes processos de inovação, recursos inovativos e formas organizacionais competentes e coesas, que revelam, por si só, uma infra-estrutura de conhecimento que suporta facilmente a aprendizagem e a inovação (GREGERSEN et al, 1997).

O reflexo do conhecimento tácito no espaço territorial pode passar pelo conceito de "meio inovador" (COOKE et al, 1994), resultado de processos de aprendizagem colectiva, como pela capacidade criativa e de inovação nas suas diferentes vertentes. Este pressuposto leva-nos à utilização de outro cenário (que pode ser considerado um patamar mais desenvolvido), que se prende com a emergência do conceito de cidades e regiões do conhecimento. Esta acaba por ter uma identidade própria e uma "cultura do conhecimento" (GREGERSEN et al, 1997).

\subsection{A cidade digital como veículo para a cidade inteligente: a Internet e o espaço urbano}

Dos conceitos de globalização, rede e tecnologia, surge-nos a conceptualização de uma sociedade "conectada", sociedade onde todos, simples cidadãos, empresas, organizações e administração pública, estão permanentemente ligados em rede e, através da qual, exercem as suas actividades. Esta sociedade "conectada" (baseada nas trocas e operações on-line, em que a informação e o conhecimento são poder e fonte máxima de competitividade e distinção económica), assenta, segundo Junqueiro (2000), na Internet e, cada vez mais, em redes similares, permitindo materializar um novo conceito (mundo virtual) que representa uma nova dimensão da realidade e do comportamento humano. A Internet constitui, sem qualquer dúvida, um dos elementos centrais da nova economia e sociedade, não só pelas consequências que a sua massificação está a causar, em todos os sectores de actividade, mas também pelo efeito profundo que teve na viabilização de uma dimensão da vida humana: a dimensão virtual (GUERREIRO, 2002). No fundo, a World Wide Web (Web) assumiu-se como a matriz da revolução digital. A Web, para além de ter colocado a Internet no centro da dinâmica económica e social, tem vindo a facilitar e a exercer pressão no sentido da adopção de modelos económicos e sociais inovadores e mais competitivos que os anteriores.

Hoje em dia, o território é uma complexa sobreposição de fluxos veiculados pela Internet e por outras tecnologias, pessoas, bens e informação, em que a "rede" e o "lugar" acabam por ser dois conceitos profundamente interligados. A Internet acelerou o movimento de convergência das 
telecomunicações, das tecnologias da informação e dos meios de comunicação. Contudo, tornouse mais importante ainda, a facilidade com que esta começou a poder ser usada de forma global e interactiva, disponibilizando todos os dias novas funcionalidades aos utilizadores. Com o incremento do número de utilizadores de Internet e com o alargamento da sua "banda" potenciouse a concretização de benefícios globais que esta encerra em si, nomeadamente no que se refere à quantidade e qualidade das aplicações digitais. Com os avanços da micro-electrónica e da informática, as relações sociais sofreram transformações radicais dado que o aparecimento de novas redes de comunicação provocou impactos directos e profundos sobre a cidade real. Urge, desta forma, uma regulação complexa de fluxos de informação, partilha de competências e fortalecimento da massa crítica de recursos humanos num determinado território e não apenas determinados actores para além das infra-estruturas. As competências, as políticas e os mecanismos correlativos apresentam-se determinantes para a gestão, distribuição, acesso e partilha da informação. Estes mecanismos, paralelos à realidade territorial aparecem no contexto de políticas adequadas à informação e ao território em causa de que é exemplo o aparecimento da cidade digital, como peças essenciais para o desenvolvimento centrado na informação e no conhecimento, elementos de poder na sociedade actual.

A compressão espacio-temporal e a maior presença, em tempo real, tem sido um dos factores de expansão das chamadas cidades digitais (GOUVEIA, 2003). Todavia, podemo-nos referir à cidade digital como uma nova plataforma social que suporta algo de intermediário, uma espécie de rede inter-comunitária que estará entre o global e o local, reforçando, assim, o conceito de "glocal". A cidade digital surge-nos como um conceito e como o resultado de uma "política territorial"; um sistema de pessoas e instituições conectadas por uma infra-estrutura de comunicação digital (como a Internet) que tem como referência uma cidade real, cujos propósitos variam e podem incluir diferentes objectivos. As cidades digitais são assim entendidas como uma primeira etapa para as cidades inteligentes, fazendo parte de uma nova forma de distribuição do fluxo de informação na sociedade. A informação e a evolução tecnológica que se encontram na base da criação destas estratégias, são importantes para o espaço urbano na medida que permitem a disseminação da informação e a construção de novos conhecimentos.

A implementação deste tipo de iniciativa potencia inquestionáveis sinergias nas dinâmicas de reconstrução do tecido social, a desburocratização das administrações e a optimização, em tempo real, dos recursos da cidade (CARDOSO et al, 2003, referindo-se a LÉVY, 2000). Na sequência do defendido por Lévy (2000), a optimização destas sinergias reside na capacidade de concretização da cidade digital enquanto um portal de interacção entre os indivíduos, a cidade e as suas instituições, já que o conceito de cidade resulta não apenas da "soma de um conjunto de tangíveis (...), mas também de uma activa rede social e relacional". Consequentemente, a cidade digital não se pode circunscrever à duplicação, no espaço virtual, dos espaços físicos. Deve, igualmente, integrar a "bidireccionalidade intrínseca ao espaço público que representa" (CARDOSO et al, 2003: 65-66). 
Segundo Lopes et al (2003), entender a cidade digital passa por compreender como os produtos e recursos digitais, assentes numa base de informação quase ilimitada, são utilizados no fornecimento de serviços destinados a facilitar a navegação social e/ou espacial num ambiente virtual ou físico. Um dos elementos base para a definição e compreensão das dinâmicas da cidade digital é a premissa de que este tipo de cidades não pode aparecer como oposição ao real. Segundo Xavier (2004), tanto o "digital como o físico tornam as coisas reais", não se devendo entender "as cidades digitais como metáforas restritas do espaço virtual". É neste contexto que é premente compreendermos a relação estabelecida (ou por estabelecer) entre o digital/virtual e o real/físico em espaço urbano, pois desta interacção decorre a finalidade principal da criação destas estratégias para as cidades.

Se é assente que a maior parte das cidade digitais funcionam como plataformas virtuais em que o território é reflectido, não é tão aceite que o virtual seja reflectido no território, isto é, que o facto de existir uma cidade digital fará com que o território seja alterado, condicionado ou diferentemente percepcionado ou planeado. É neste sentido que, mediante a nossa percepção, as relações de génese entre o físico e o virtual se apresentam, na actualidade e em alguns casos, extremamente dificultadas. No nosso entender, a relação entre o digital e o real tem que ser mútua e contínua. A estrutura física das cidades digitais, em detrimento de um digital mais desenvolvido, está a ser cada vez mais valorizado, servindo de referência para novos projectos.

O território, nesta perspectiva mais alargada, poderá ser condicionado, sendo que as cidades digitais poderão criar, segundo Guerreiro (2002), "uma nova geografia social e económica, pela promoção da competitividade das suas comunidades e pelas sinergias com as fronteiras físicas do território". Se é verdade que o território, enquanto espaço limitado e organizado por sistemas de proximidade física e geográfica, se opõe ao ciberespaço, dimensão virtual, sem hierarquias e regras rígidas, também se pode afirmar que estes não são totalmente convergentes e que a sua relação poderá ter que partir de uma dimensão mais social, privilegiando os modos transversais de relação e a fluidez das suas estruturas.

\section{AS CIDADES E TERRITÓRIOS DO CONHECIMENTO COMO NOVAS ESTRATÉGIAS DE DESENVOLVIMENTO}

\subsection{A cidade inteligente no quadro do desenvolvimento territorial}

Da relação entre a criatividade e o conhecimento, poderá surgir um novo conceito que integra as questões territoriais, interconectando o digital com o real - a cidade inteligente. A capacidade das cidades para gerarem e promoverem a inovação, a aprendizagem colectiva e o conhecimento, passa pela criação, nos territórios locais e regionais, de estruturas capazes de promover e assegurar estes elementos territorialmente em conjunto com a dimensão digital. Neste quadro, a 
relação estreita entre o tangível e o intangível é a grande referência neste conceito de cidade inteligente, onde a localização, tanto em forma de infra-estruturas, como de conhecimento, é essencial na sobreposição do digital sobre o real e vice-versa, sendo o inteligente um patamar posterior ao digital. Estes territórios estão munidos de um meio de informação, cientificidade e inovação e são receptivos à mudança imposta pela informação e globalização, sendo a sua flexibilidade reflectida no espaço, considerando-os espaços inteligentes. A região inteligente, à luz de uma comunidade do conhecimento, aparece-nos como uma região geográfica complexa, formada por cidades e locais de influência onde a tecnologia flui com maior facilidade, na perspectiva da produção, uso e disseminação.

Apresentando-se como "regiões dinâmicas de inovação" (FLORIDA, 1995; KOMNINOS, 2002; RADOVANOVIC, 2003), as cidades e regiões do conhecimento inserem-se num ambiente favorável ao desenvolvimento tecnológico, económico e social, estando na presença de um forte relacionamento dos sectores produtivos com processos de I\&D, bem como universidades, incubadoras, centros tecnológicos, significando uma mão-de-obra qualificada, um grande investimento em inovação e investigação e uma economia voltada para o conhecimento e para o desenvolvimento científico. Nesta perspectiva, tanto nos domínios tangível como intangível, as apostas e políticas (urbanas, tecnológicas e do conhecimento) definidas pelas entidades responsáveis são preponderantes na concertação de estratégias para os territórios (Figura 2).

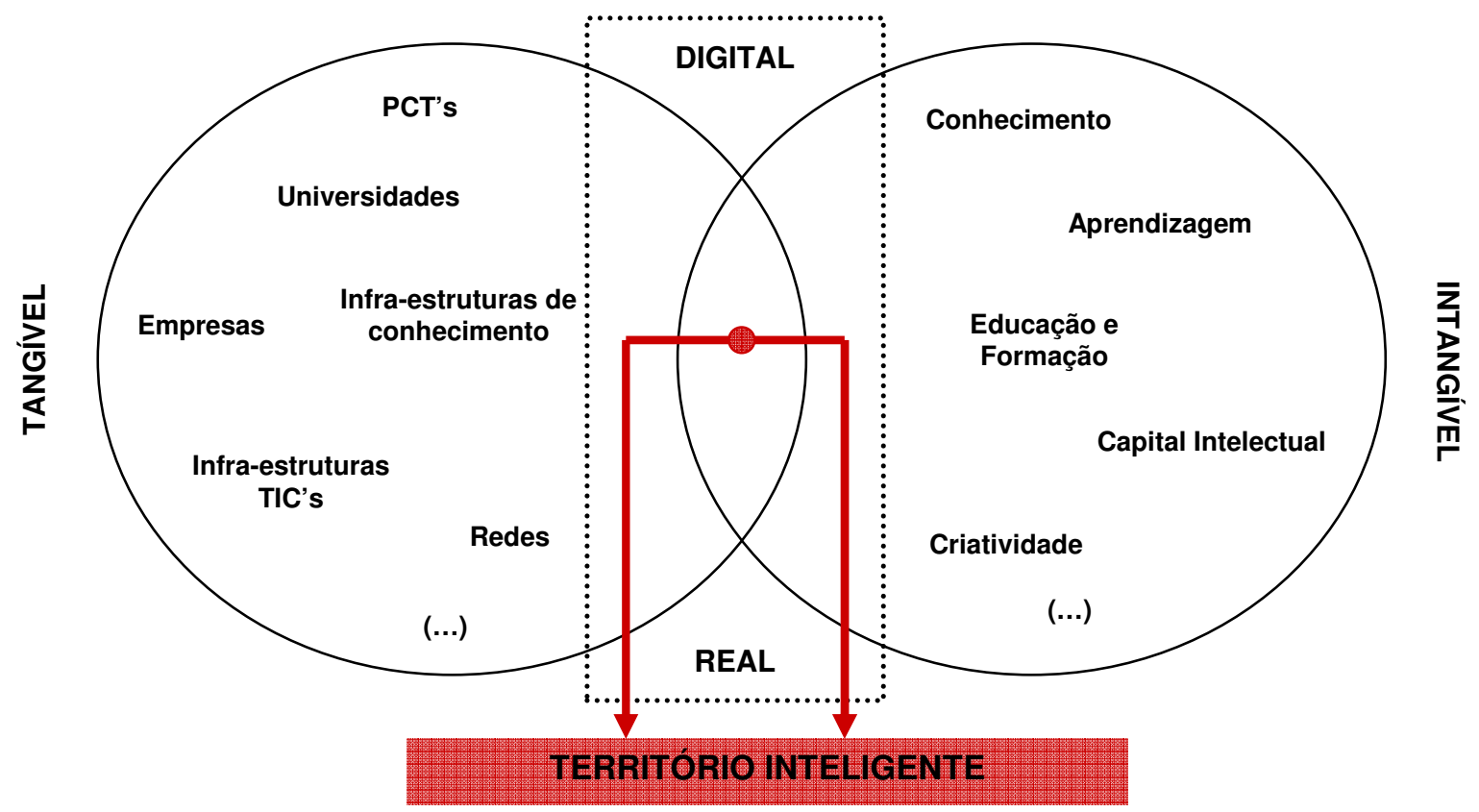

Figura 2. Ligações funcionais das cidades digitais e inteligentes

Fonte: Adaptado de KOMNINOS, 2002:200 
As denominadas cidades e/ou regiões inteligentes privilegiam no território o conhecimento e a aprendizagem, bem como os relacionamentos possíveis entre as diferentes bases institucionais (HUDSON, 1999). Deste modo, Florida (1995:527), com base no conceito inicialmente apresentado, considera que as learning regions, que começam a ser pontos nodais para a criação de conhecimento e para a aprendizagem na nova era do global e do capitalismo baseado no conhecimento, funcionam como colectores e locais de armazenamento de conhecimento e ideias que proporcionam as infra-estruturas e a atmosfera fundamental à circulação e desenvolvimento do conhecimento, das ideias, da aprendizagem e da inovação. As learning regions são consideradas territórios bem posicionados para "desenvolver opções e soluções concertadas de cooperação e integração económica de tipo territorial e funcional” (SERRANO et al, 2005: 101).

A cidade inteligente, pensada de forma conceptual à luz da learning region (FLORIDA, 1995), solidificou-se, segundo Komninos (2002), com uma série de projectos-piloto que permitiram a gestão, por parte das cidades, da informação e do conhecimento, qualificando a cidade como um meio digital e inteligente. Esta é encarada como uma nova estratégia de desenvolvimento em que existe um forte incremento da competitividade entre os espaços urbanos. Todos estes projectos e aplicações abriram, assim, novos caminhos para as cidades e regiões inteligentes. Segundo o Intelligent Community Forum (ICF), a comunidade inteligente (ou cidade inteligente, wired city, smart city e e-city), num primeiro momento, define-se pela largura da sua banda de acesso, aplicável às cidades, mas também a regiões e países que vêm na Internet e nas redes de informação tecnológica instrumentos essenciais para o desenvolvimento. Todavia, a sua distribuição a diferentes escalas, configura desigualdades e cria problemáticas na relação entre inclusão e info-exclusão, dependendo das opções e apostas de desenvolvimento dos países, regiões e cidades no que concerne a este tipo de infra-estruturas e estratégias. As novas tecnologias de informação e comunicação terão de funcionar como plataformas de apoio ao desenvolvimento assente nas estruturas físicas de educação, ensino, investigação, inovação, governo local, regional e nacional, cultura e comércio.

A comunidade inteligente terá nos seus cidadãos e infra-estruturas a força motriz de utilização e adaptação a esta nova forma de pensar, permitindo-Ihes a dotação de instrumentos que lhes possam dar vantagens competitivas em novos empregos, novas sociabilidades e maior flexibilidade e competitividade na economia. Desta forma, o ICF acrescenta que a infra-estrutura de banda larga, a força de trabalho dotada de conhecimento, a inovação, a democracia digital e as novas actividades ligadas ao marketing e design, são factores críticos para a criação com sucesso de novas comunidades inteligentes.

Nesta perspectiva, para Simmie et al (2002), a learning region é "um território caracterizado por processos territoriais de inovação, por processos de territorialização das empresas e por processos de aprendizagem", muito para além do inicialmente definido pelo ICF, isto é, o determinismo ligado à largura da banda das diferentes áreas. Todavia, segundo Simmie (1997), só 
podem ser consideradas cidades inteligentes, aquelas onde o tangível (quantificado em infraestruturas e serviços) e o intangível (capital intelectual, recursos humanos e conhecimento tácito) constituem a base da comunicação digital e trocas de ambiente nestas cidades e territórios.

\subsection{O tangível e o intangível: das ilhas de inovação ao conhecimento como vectores estratégicos para a construção de territórios inteligentes}

Da relação entre o tangível e o intangível, entre o físico/real e o digital/virtual, retiramos a premissa que os diferentes actores, quer locais quer regionais, são os "principais vectores de transmissão territorial do conhecimento, é a natureza desses relacionamentos que está, em grande medida, na base da qualidade do sistema territorial de aquisição e acumulação de conhecimento" (SERRANO et al, 2005: 102). A cidade inteligente é, aqui, fruto dos relacionamentos que vão para além da "simples" relação entre o físico e o virtual, isto é, depende das ligações entre as diferentes esferas de acção (locais e regionais, da cidade ou da região), baseadas em modelos que contemplam o território, a inovação, o capital intelectual, o conhecimento e a aprendizagem, estes últimos de forma localizada, colectiva e interactiva. Neste contexto, a cidade inteligente assume o seu principal sentido na conjugação entre o espaço real e o espaço digital, nos domínios tangível e intangível (Figura 2).

Da charneira desta relação, na nossa perspectiva, surge-nos uma aproximação mais específica do conceito de cidade do conhecimento, isto é, uma cidade de suporte digital, mas que contempla e tem como objectivo a valorização do território. Consideramos uma cidade e/ou território inteligente quando a existência ou criação de um espaço digital/virtual está relacionado com uma comunidade de pessoas e produtores real, caracterizados por um elevado nível de instrução e uso de inovações. Logo, as aplicações tecnológicas têm que ser implementadas a par de "ilhas de inovação" reais onde os territórios inteligentes assumam, segundo Komninos (2002), em si mesmos, duas componentes principais: uma comunidade humana, definida geograficamente, em que se desenvolvem redes económicas, sociais, institucionais e de informação que potenciam o conhecimento e a inovação; e, por outro lado, um conjunto de infra-estruturas baseadas nas TIC's e uma diversidade de instrumentos que optimizem a gestão do conhecimento, o desenvolvimento tecnológico e a inovação, bem como todas as acções, limites e contextos do ciberespaço e das plataformas digitais.

Consequentemente, usamos o termo "cidade inteligente" para caracterizar áreas (comunidades, bairros, distritos, cidades, regiões) que tem a competência, por um lado, de albergar em si o ensino, o desenvolvimento tecnológico e os procedimentos de inovação, e, por outro, espaços digitais, processamento de informação, transferência de conhecimento e instrumentos tecnológicos (KOMNINOS, 2002:198), sendo que cada cidade digital não é necessariamente inteligente, mas todas as que são inteligentes têm uma componente digital associada a elas. Neste contexto, não é suficiente desenvolver infra-estruturas digitais e de transferência de 
conhecimento para encararmos um território como inteligente. A banda larga e os cabos de fibra óptica, entre outros, não são por si só, provas e significado de "inteligência", esta é dependente de faculdades que se prendem com a competência, o talento, o coeficiente de inteligência e a adaptação social dos indivíduos (FLORIDA, 1995; SASSEN, 2001; KOMNINOS, 2002; SERRANO et al, 2005).

A visão muitas vezes apresentada é, na nossa opinião, redutora, pois separa claramente os dois domínios, aspecto que não coabita com a nossa forma de pensar (em que estas duas dimensões deverão estar interligadas). Consequentemente, temos que encarar a presente cidade como resultado da forte interacção entre o digital e o físico, sendo que ocorre em todas as funções da cidade onde isso é possível. Esta interacção entre o espaço físico e o digital acontece nas actividades do quotidiano e na forma como estas actividades acontecem no espaço físico e electrónico de um local de trabalho, de uma habitação ou de uma comunidade.

Como aponta Lopes et al (2003), é necessário desenhar espaços digitais de maneira a que respeitem a funcionalidade e associações simbólicas que os espaços físicos contêm. Logo, devese considerar que o incremento que se verifica no uso das TIC's afecta a nossa percepção e utilização das comunidades físicas e sociais que nos rodeiam. O desafio com que nos deparamos quando falamos no desenvolvimento de cidades e regiões inteligentes centra-se na construção de uma relação sólida entre o digital e o físico, que aproveite as vantagens entre eles existentes e conduza, como objectivo central, para a valorização e potencialização do território e da sociedade.

Contudo, numa cidade inteligente, por oposição ao apontado anteriormente, a relação entre o real e o virtual acaba por ser, muitas das vezes, limitada por um dos domínios ou pela interconexão dos dois (FLORIDA, 1995; MITCHELL, 1999; SASSEN, 2001; KOMNINOS, 2002; SIMMIE et al, 2002; GOUVEIA, 2003). O princípio da transferência de funções reais para os espaços virtuais mantém-se, mas o cerne está ligado, de forma mais específica, ao conhecimento, investigação, educação e desenvolvimento tecnológico. Estas funções, como integram uma enorme quantidade e diversidade de informação, são um campo oportuno para o uso das tecnologias da informação e da comunicação, gestão de conhecimento e tecnologias de comunicação remotas. Neste contexto, as funções primárias que, numa cidade inteligente, podem ser desenvolvidas no espaço virtual estão intimamente ligadas com os ambientes inovadores, como a investigação, desenvolvimento tecnológico, transferências de tecnologias, serviços de desenvolvimento do produto, cooperação e redes tecnológicas (Figura 3).

A cidade inteligente, no quadro actual, pode ser considerada "uma ilha (comunidade) de inovação tecnológica que integra as funções de desenvolvimento de inovação, reais e digitais/virtuais“" (KOMNINOS, 2002: 201), ou noutra perspectiva um conjunto de "ilhas", onde as suas funções se prendem com a produção de conhecimento (I\&D), transferência de tecnologia, entre outros, sendo 
que estas funções são desenvolvidas em ambos os espaços, com interacção directa dos indivíduos no espaço real e, através das TIC's, no espaço virtual.
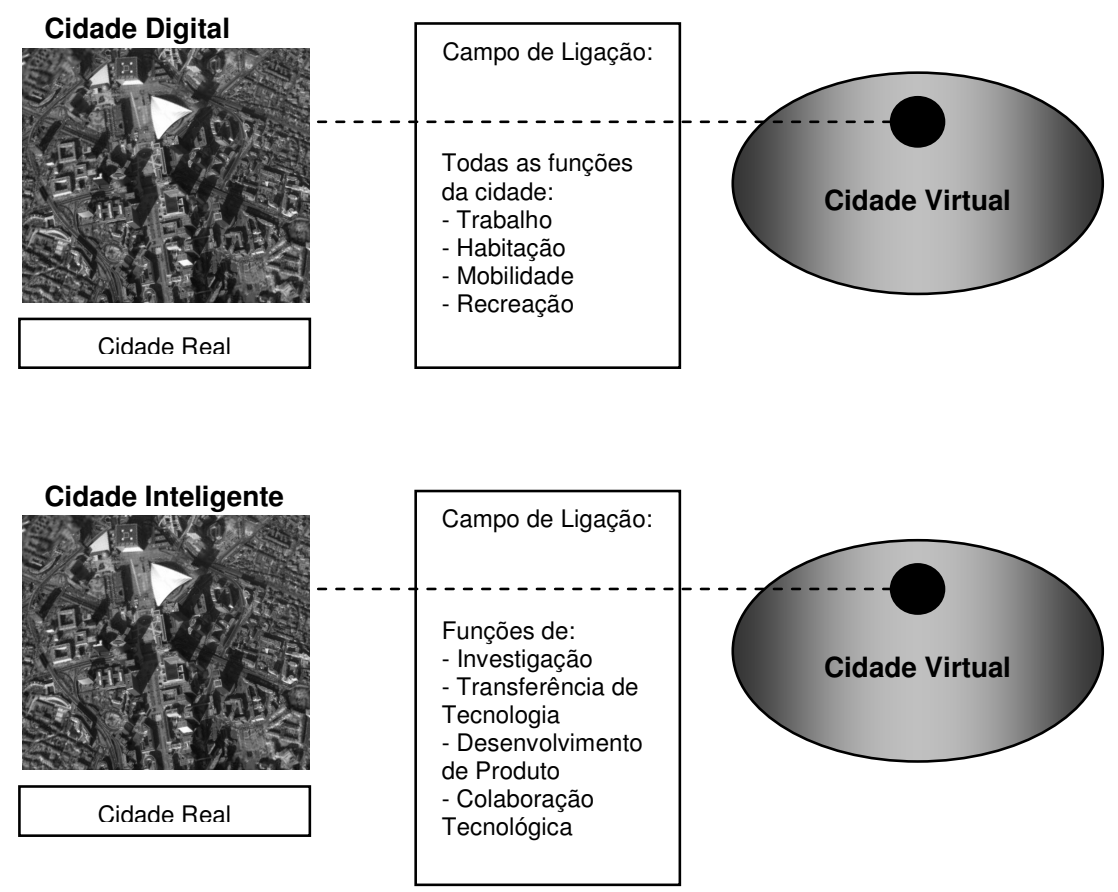

Figura 3. Ligações funcionais das cidades digitais e inteligentes

Fonte: Adaptado de KOMNINOS, 2002: 200

Neste sentido, existem, segundo Komninos (2002), três componentes básicas na cidade inteligente: uma ilha de inovação formada por uma comunidade de pessoas, actividades de produção, troca e outras; um sistema de inovação virtual que inclui, por um lado, instrumentos de gestão de conhecimento e, por outro, um sistema de tecnologias de informação para provisão online de informação e serviços de inovação; e, por último, a inter-relação entre o sistema de inovação real e o virtual, isto é, o uso do último pela comunidade científica (Figura 4). Estes elementos estão relacionados com os dois espaços, o real e o virtual, e a sua relação cria um novo "sistema de inovação real-virtual" (KOMNINOS, 2002).

A conjugação entre os sistemas de inovação real e virtual requer que as funções da "ilha" de inovação possam ser reconstruídas para que seja fiável trabalhá-las no espaço virtual, sendo que a "digitalidade" de uma função não é uma simples projecção desta no espaço virtual, esta pressupõe "uma desmaterialização e decomposição para os seus elementos base, codificação dos seus procedimentos e reconstrução com o uso de métodos e tecnologias que substituam a complexidade da interacção humana directa e a criatividade humana em lidar com o inesperado, com circunstâncias para além das regras e na resolução de problemas desconhecidos" (KOMNINOS, 2002: 202). 


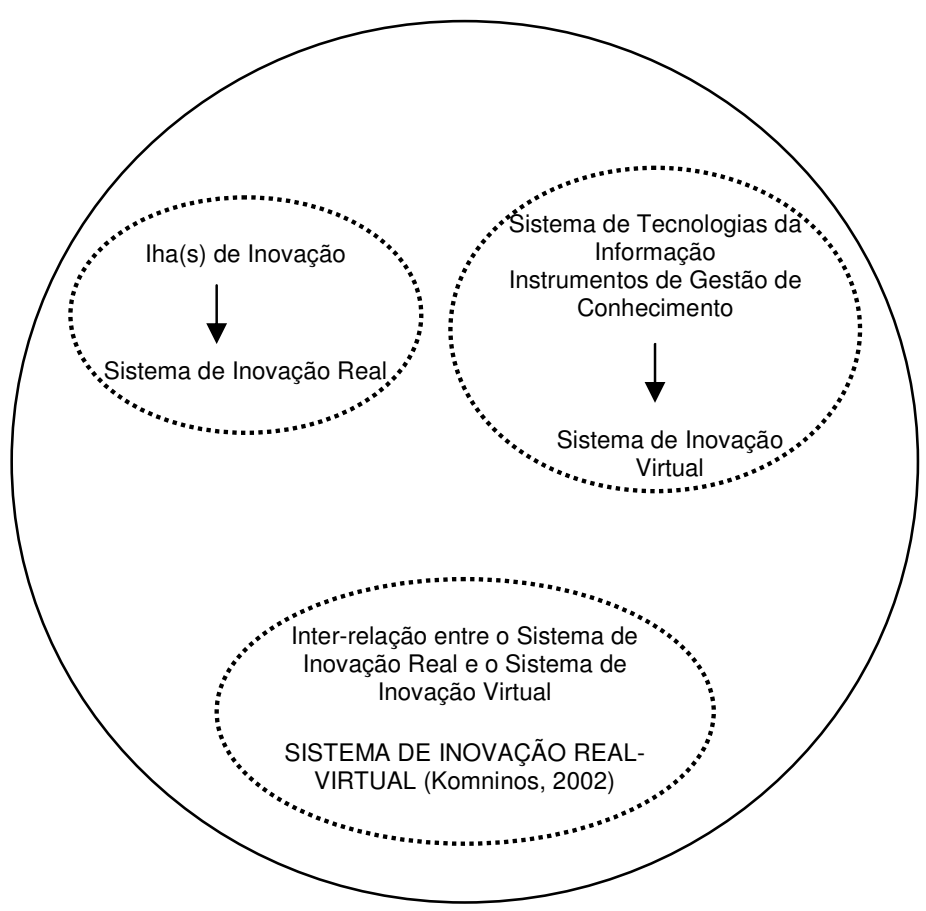

Figura 4. Elementos base da cidade inteligente

Fonte: Autores, baseado em KOMNINOS, 2002

É de referir, igualmente, que o sistema virtual de inovação inclui instrumentos de gestão de conhecimento que se relacionam no ciberespaço com agentes inteligentes e sistemas de novas tecnologias de informação e comunicação, em operações on-line de funções relacionadas com o conhecimento e a inovação. Dentro deste item podemos destacar a Internet, as aplicações multimédia, os serviços on-line, a educação remota, a transferência de dados, informação e conhecimento, entre outros. Este ambiente virtual de suporte do sistema de inovação e conhecimento pode ser descrito como uma combinação de redes de comunicação, serviços remotos, informações de bases de dados de mercado e outras, bem como uma rede de fortes relações entre compradores, empresas, produtores e usuários. Desta forma e segundo Komninos (2002), podemos falar em cidade inteligente na sua plenitude, quando o ambiente virtual de inovação é criado como uma projecção do sistema de inovação real, que facilita e suporta as funções do sistema real. O sistema virtual de inovação inclui instrumentos de gestão de conhecimento que se relacionam no ciberespaço com agentes inteligentes e sistemas de novas tecnologias de informação e comunicação, em operações on-line de funções relacionadas com o conhecimento e a inovação. Destacam-se neste quadro a Internet, as aplicações multimédia, os serviços on-line, a educação remota, a transferência de dados, informação e conhecimento, entre outros.

A inter-relação e a integração de vários níveis (distrito, meios inovadores, funções de conhecimento e inovação e sistema de inovação), geram um sistema/distrito de inovação realvirtual, onde as relações entre o conhecimento e as comunicações são optimizadas pelo uso das tecnologias da informação e tecnologias de gestão de conhecimento. Estas relações formadas por 
aplicações real-virtual incrementam a capacidade de uma comunidade criar um distrito pleno de criatividade, não-estandardização, inovando constantemente e com grande competitividade dos seus produtos. A conexão entre os sistemas de inovação virtual e real transmite-nos a função da ilha de inovação reflectida no espaço virtual, desmaterializando os conteúdos e codificando alguns tipos de conhecimento colectivo. Neste "sistema de inovação real-virtual" (KOMNINOS, 2002), a componente virtual torna os processos na ilha de inovação mais fáceis e rápidos, isto é, o desenvolvimento do conhecimento, a transferência de tecnologia, a criação de novos produtos e procedimentos e a colaboração são, assim, facilitados, caminhando na direcção a uma nova economia com um maior crescimento e desenvolvimento.

Na sequência, Komninos (2002) aponta quatro funções da cidade inteligente: a produção de conhecimento (I\&D); a transferência de tecnologia; o financiamento da inovação; o desenvolvimento de novos produtos e o trabalho em rede, às quais podemos juntar 0 desenvolvimento de novos serviços, os diferentes processos de produção e as actividades de colaboração tecnológica. Estas funções são desenroladas em dois espaços em paralelo, o espaço real, como interacção humana directa, e pelo espaço virtual, por via das novas tecnologias de informação e de comunicação, como é o exemplo da Internet. Posteriormente, em 2006, este mesmo autor reformulou as funções iniciais que tinha lançado para a cidade inteligente, apontando quatro "novas" principais funções para a cidade inteligente assentes na lógica do cruzamento do digital e do real: (1) a inteligência estratégica colectiva; (2) a transferência de tecnologia; (3) a inovação colaborativa; e, por último, (4) a promoção de clusters e lugares, formando desta forma uma nova "arquitectura" da cidade inteligente.

No que se refere à inteligência estratégica colectiva, podemos afirmar que a inteligência estratégica é um campo da inovação de grande importância na sociedade da informação em que vivemos na actualidade, verificando-se desta forma, que as cidades hoje em dia apostam numa inteligência estratégica colectiva em que o armazenamento, criação e disseminação de informação e conhecimento estão depositados numa relação entre elementos como as pessoas, a comunidade e o cluster de negócios. Assim, este tipo de inteligência, ao contrário da inteligência ligada aos negócios, é cooperativa, resultando a interligação entre diferentes actores na partilha de conhecimento de forma tácita, cumulativa e localizada. Com a conexão entre os ambientes real e uma nova plataforma digital cooperativa, desenvolvem-se novos campos na esfera do conhecimento, como por exemplo, a auditoria tecnológica e o benckmarking. A auditoria tecnológica e o mercado permitem o armazenamento, análise, compreensão e difusão de informação de forma sistemática, integrando num mesmo patamar o conhecimento de novos produtos, tecnologias, estatísticas tecnológicas, indicadores de performance e informações de mercado preços entre outros (KOMNINOS, 2006). Assim, a partir de plataformas digitais, a base da inteligência estratégica colectiva reside na utilização destas para o armazenamento em repositórios digitais, facilitando desta forma a sua consulta e troca. Por outro lado, o benchmarking permite comparar situações e recolher das comparações as suas boas práticas e lições para 
casos específicos, construindo, deste modo, um conhecimento acumulado e uma inteligência versátil e adaptada aos diferentes casos.

A transferência de tecnologia pressupões, segundo Komninos (2006) a passagem de know-how de instituições de I\&D para outras organizações, sendo que neste sentido a par de inteligência estratégica colectiva, é um dos elementos mais importantes para a construção e arquitectura da cidade inteligente, materializando-se em licenciamentos, atribuição de patentes, I\&D cooperativo, spin-off's, entre outros. Na lógica da cidade inteligente vista como a relação entre as esferas real e digital, são de sublinhar as novas funções do digital na prossecução do processo de transferência de tecnologia. Neste contexto, "as plataformas digitais facilitam a transferência de tecnologia em bases de dados de tecnologias de resultados de I\&D" (KOMNINOS, 2006: 6).

A inovação colaborativa corresponde a uma nova forma de inovação que reconhece as comunidades e as redes como condições fundamentais para a inovação. As interacções com comunidades científicas de diferentes campos temáticos, papéis, capacidades ao longo da cadeia de inovação, torna-se um elemento importante para a criação de novos produtos e para o enriquecimento da capacidade criativa e inovadora dos agentes do sistema de inovação. Neste sentido, a inovação já não é algo que surge do individual, mas de um colectivo de inteligência estratégica e de relações entre elementos do sistema de inovação, economia, indústria e sociedade. Contextualmente, as plataformas digitais aparecem, na sua relação com o físico, como ambientes virtuais que facilitam a cooperação e transferência entre os agentes, materializando-se na formação de clusters virtuais que reflectem as relações no território e estão munidos de instrumentos de gestão de inovação, design, criatividade, mercado, auditoria e marketing. Estas plataformas, como é exemplo o ONLI Project ${ }^{4}$, oferecem ambientes colaborativos para o desenvolvimento de produtos, resolução de problemas passo-a-passo, um acréscimo de novas fases e ideias para o desenvolvimento do produto, novas metodologias e instrumentos, e, aprendizagem a experimentação através de simulação (KOMNINOS, 2006: 7). O resultado desta função é o "incremento das capacidades humanas de inovação, devido à colaboração e disponibilização de tecnologias avançadas e instrumento de desenvolvimento de produto, até mesmo ao mais remoto trabalhador do conhecimento" (KOMNINOS, 2006: 7).

Por último, temos obrigatoriamente que falar na promoção de clusters e lugares, que hoje em dia parece fortemente ligada às novas tendências das relações entre os territórios inteligentes e o marketing territorial estratégico. Assim, com base na relação entre o digital e o real, temos que sublinhar a importância da valorização dos instrumento virtuais, nomeadamente a Internet, para a promoção dos territórios reais através de marketing directo, atracção de pessoas e investimentos, trocas comerciais, e-learning, e-commerce, e-health, entre outros. Neste contexto, se estas plataformas digitais representarem plenamente o conceito de cidade inteligente, isto é, traduzirem e repercutirem o território real no domínio virtual e vice-versa, podemos concluir que estão a ser

\footnotetext{
${ }^{4}$ Rede Europeia de Inovação - www.newvwnturetools.net
} 
valorizados lugares, cidades, regiões e clusters. Assim, existirá uma conexão entre duas grandes redes, uma digital e outra real, sendo que os espaços virtuais facilitarão e desenvolverão novas relações no espaço físico, bem como a redução de custos de transacções, logística, os processos de marketing, publicidade e promoção dos actores, o conhecimento, informações, regras, regulamentos, atribuição de incentivos, parcerias, serviços e transferência de informação, tecnologia e conhecimento.

Consequentemente, é urgente desenvolver iniciativas estratégicas para as cidades e regiões, num formato de "acções-piloto" perfeitamente adaptadas à velocidade, capacidade de absorção e patamar tecnológico de cada território, de modo a que em função dos resultados que vão sendo observados se possa, progressivamente, ir alargando o alvo de intervenção e os campos temáticos dos projectos. Neste contexto, torna-se importante avaliar e corrigir o implementado até ao momento, com vista a potenciar e calibrar as iniciativas, sem nunca esquecer o território e a população. Desta forma, Radovanovic (2003) lança uma nova perspectiva acerca da cidade inteligente que não se prende apenas com a questão tecnológica. A cidade, neste contexto, deve ser capaz de gerir os seus recursos, principalmente os humanos, apostando no capital intelectual, na educação, sendo esta última importantíssima para a criação de "inteligência territorializada", intersectando o conceito de cidade inteligente com o paradigma do capital intelectual.

Em suma, as "cidades e regiões inteligentes são territórios com grande capacidade para a aprendizagem e inovação, que são construídas com base na criatividade da sua população, das suas instituições de criação de conhecimento e na sua infra-estrutura digital de comunicação e gestão de conhecimento (...) constituindo sistemas de inovação avançados, nos quais os mecanismos institucionais de criação e aplicação de conhecimento são facilitados por espaços digitais e instrumentos on-line para comunicação e gestão de conhecimento" (KOMNINOS, 2006: 1). Neste sentido, não existem dúvidas de que a componente digital faz com que os processos num ambiente inovador se tornem mais simplificados e rápidos, com o desenvolvimento do conhecimento, transferência de tecnologia, criação de novos produtos e procedimentos, trabalho em rede e cooperação, tendo todos estes aspectos não só uma enorme importância para a nova economia do conhecimento, como também para o incremento de condições de prosperidade neste novo século. $O$ inteligente surge, assim, como uma nova estratégia a diferentes escalas, sendo neste sentido fundamental analisarmos diferentes casos a diferentes escalas, para percebermos totalmente o conceito de cidade inteligente.

\section{O MARKETING TERRITORIAL E OS TERRITÓRIOS BASEADOS NO CONHECIMENTO: UMA PRIMEIRA ABORDAGEM}

As cidades e as regiões coabitaram desde cedo com as lógicas de mercado e com os princípios gerais do marketing, espaços que se reflectiam como conglomerados de relações entre empresas, instituições, residentes e visitantes. Contudo, o marketing territorial tem vindo a ser utilizado como 
ferramenta de promoção económica das cidades, na realização de grandes eventos, em reestruturações urbanas profundas e para a promoção turística dos territórios, das empresas e das pessoas. Após a fase em que o marketing dos territórios simbolizava promoção dos lugares, agora observa-se que os territórios, no decorrer do tempo, tentam "assumir características específicas e especiais num processo de competitividade acrescida e global" (CIDRAIS, 1998: 15). Deste modo, o marketing territorial afirma-se como um processo de gestão territorial, de descentralização de poder e busca de desenvolvimento local, sendo um integrador das vantagens competitivas do lugar numa óptica de desenvolvimento sócio-económico e territorial (CIDRAIS, 1998; KOTLER et al, 1999), à semelhança do que se encontra na génese do conceito de cidade inteligente.

O "place marketing" ("city marketing", "marketing territorial", "marketing urbano", "marketing do lugar", entre outras denominações) surge como um dos elementos centrais do planeamento estratégico das cidades e regiões, partindo das suas singularidades e especificidades, integrandoas e projectando-as num contexto global de competitividade, tendo em conta a sua vocação e visão, promovendo-as e afirmando-as. Segundo Cidrais (1998), os agentes territoriais assumem aqui o papel mais importante para o desenvolvimento local, na concertação de acções, na salvaguarda de recursos e na proliferação de dinâmicas assentes numa forte organização das inter-relações entre agentes territoriais. Neste sentido, o marketing territorial tem vindo a ser discutido por inúmeros autores (KEARNS et al, 1993; NOISETTE et al, 1996; CIDRAIS, 1998; KOTLER et al 1999; BENKO, 2000; VAN DEN BERG et al, 2002), definindo-se a partir de duas grandes aproximações. Num primeiro momento, considera-se marketing territorial "um instrumento de apoio às estratégias de desenvolvimento das cidades e das regiões que se integra numa lógica racional de capitalismo flexível em que o cruzamento entre o imaterial (comunicação e conhecimento) e as pessoas e as entidades ganha relevância" (CIDRAIS, 1998). Deste modo, o marketing adaptado ao território reflecte-se num conjunto de actividades cujo objectivo se prende com a optimização das funções urbanas, características e condições, quer para os seus habitantes e para as empresas, quer para os seus turistas ou visitantes, sendo encarado como um conjunto de actividades de suporte ao desenvolvimento de um lugar, região ou país através da melhoria da sua capacidade concorrencial (colocando o território "no mercado" ou fortalecendo o seu "ranking" e posição no mesmo). É, assim, para os diferentes territórios, uma matriz de desenvolvimento sustentado assente num plano estratégico previamente delineado e coeso.

Uma outra perspectiva do marketing territorial e/ou urbano, reside na associação entre a "venda dos lugares" (KEARNS et al, 1993) e a cidade, traduzindo-se num incremento da comodidade dos espaços e dos seus indivíduos, sendo os lugares invólucros de potencial social e económico em constante competitividade com outros mercados abertos, com partilha de capital e com inovação, no contexto da nova economia e da sociedade da informação e do conhecimento e no quadro da emergência das cidades inteligentes. De forma a suportar a elevada competitividade, a gestão urbana terá que se organizar eficientemente e aceder a estratégias orientadas pelo marketing 
numa linha de competição e interdependência entre cidades num contexto de internacionalização e alargamento das escalas espaciais das relações económicas.

No actual contexto de globalização dos territórios e da sua dotação de características ligadas à "inteligência" tecnológica e territorial, o marketing territorial assume uma estreita necessidade em desenvolver estratégias arrojadas de afirmação, promoção e mobilização de recursos em busca da atracção e fixação de bens, capital humano, recursos financeiros e investimento, pois só desta forma os territórios entrarão no "mercado global" de forma competitiva. O planeamento estratégico, no quadro dos territórios do conhecimento, pode ser perspectivado na óptica do marketing territorial, dando origem, nas suas diferentes esferas, ao denominado por "marketing estratégico do território", resultando da "actuação dos diferentes agentes e da comunicação que os diversos componentes do território estabelecem com os públicos que se relacionam" (CIDRAIS, 1998: 44). Neste âmbito, o marketing territorial deve ser o processo estratégico de análise e gestão das condições de competitividade das cidades e regiões de forma integrada, complexa e participada, pressupondo uma outra forma de observar e pensar o território. Este apresenta uma panóplia de estratégias para a sustentabilidade social, económica, cultural e política, podendo ser responsável pela regulação e planeamento do espaço territorial e digital (NOISETTE et al, 1996).

Os lugares, cidades e regiões têm necessidade de desenvolver um planeamento estratégico de marketing a par daquele que tem sido desenvolvido para os produtos nas empresas ao longo dos anos. A emergência das chamadas cidades e regiões do conhecimento, na sua concepção global, pode funcionar como uma matriz para o desenvolvimento de processos estratégicos de marketing territorial. Contudo, estes processos são bem mais difíceis pois são aplicados a espaços territoriais, onde um grupo vasto de actores interagem e onde as dinâmicas são mais importantes do que aquelas que verificamos nas empresas. Deste modo, como nos aponta Kotler et al (1999), o processo estratégico de marketing territorial é deveras complexo, contemplando cinco grandes etapas essenciais e representativas: uma auditoria do lugar/cidade/região (muitas das vezes através de instrumentos como o benchmarking e a análise SWOT); a formulação de uma visão e definição de grandes metas e objectivos; a formulação de uma estratégia; elaboração de um plano de acção; e, por último, a implementação e o controle.

A relação entre a cidade inteligente e o marketing territorial depende de uma visão estratégica, das condições espaciais e económicas, da liderança, do suporte político e social, da performance destas regiões do conhecimento, quer ao nível real quer na dimensão virtual, em diferentes esferas de acção (económica, social, organizacional, entre outras) e da cooperação e organização, formulando-se um posicionamento para o território (Figura 5). Considerando a capacidade organizativa como a capacidade de envolver os diferentes actores e, com a sua contribuição, criar novas ideias, desenvolver novas políticas e implementá-las para um desenvolvimento mais sustentado, temos que considerar a existência de alguns factores determinantes que contribuem para estas dinâmicas: a organização administrativa; as redes 
estratégicas, a liderança, a visão e estratégia, as condições espaço-económicas e o suporte social (VAN DEN BERG et al, 1999). Como é geralmente aceite, as estratégias de marketing territorial são "instrumentos à disposição das cidades e regiões para a promoção do desenvolvimento baseado num planeamento estratégico" (CIDRAIS, 1998: 8).

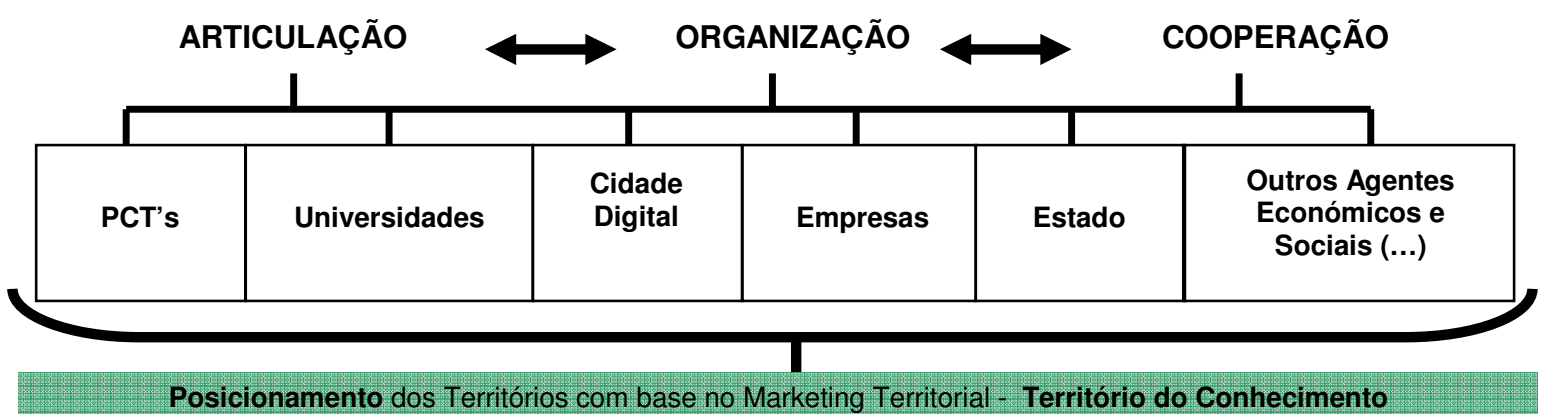

Figura 5. Capacidade organizativa e posicionamentos dos territórios do conhecimento numa óptica do marketing

Considerando o planeamento estratégico como um conceito previamente adquirido, um instrumento que oferece uma visão global e inter-sectorial a longo prazo, que formula objectivos e centra recursos em domínios críticos, é essencial que o marketing territorial seja um dos seus complementos e que os seus objectivos adquiram um cariz de desenvolvimento sócio-económico para os diferentes segmentos, esferas e elementos da cidade do conhecimento (Figura 6).

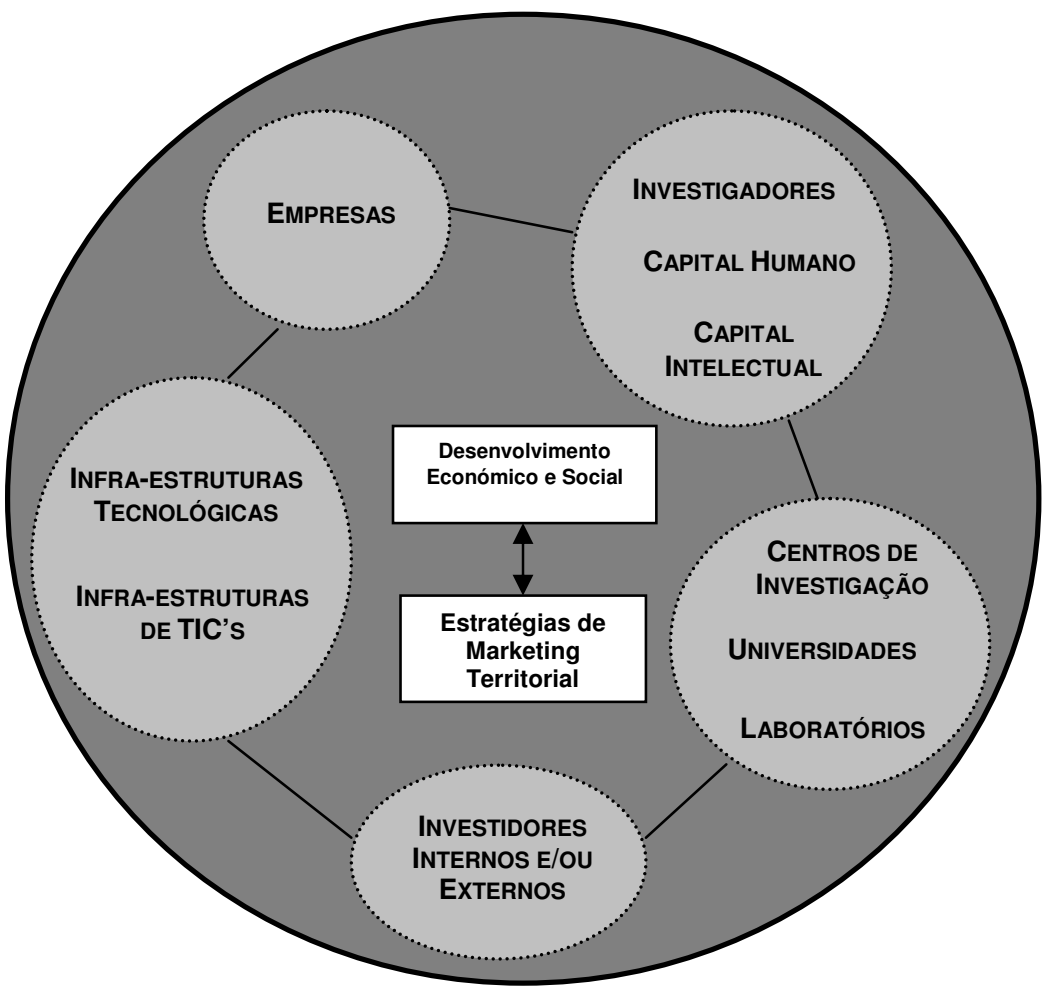

Figura 6. Possíveis segmentos seleccionados e elementos definidos para o marketing territorial numa cidade do conhecimento 
Tendo em conta a especificidade, a visão e o posicionamento dos territórios do conhecimento, numa óptica de marketing territorial estratégico, existem alguns elementos que podem, de forma interligada, compor o panorama de aposta e valorização. Neste sentido, a "rede" que se deverá constituir terá que contemplar diferentes agentes e factores (como as empresas, a investigação e o desenvolvimento, centros de investigação, universidades e laboratórios, os investidores, quer externos quer internos, as infra-estruturas tecnológicas e digitais, e o estado; entre outros) que neste contexto, muitas das vezes, são comuns à estratégia das cidades e regiões inteligentes.

A cidade tendo em conta as suas características de base (clima, composição do tecido urbano e económico, posição geográfica, história, etc.), pode definir uma estratégia coerente que the dê uma nova imagem, novas representações e sirva de base para obter vantagens competitivas no mundo virtual e real, tratando-se de uma cidade do conhecimento. O posicionamento da cidade num contexto cada vez mais competitivo, depende das infra-estruturas digitais e reais, das políticas adoptadas e da forma como se valoriza no global. Trata-se de "optar por uma estratégia de diferenciação que permita dar uma personalidade clara à cidade para que obtenha um lugar preciso na consciência dos indivíduos, dos decisores (...), dos meios de opinião, etc." (BENKO, 2000: 6-7). Partilhando da criatividade, do conhecimento, das novas tecnologias presentes na sociedade nesta nova forma de pensar a economia e a cidade, o marketing territorial terá que apostar repetidamente numa promoção e valorização que esteja directamente relacionada com o desenvolvimento desse espaço específico. Por outro lado, a percepção da cidade terá que mudar de uma visão mais fordista, onde as indústrias tinham um lugar cimentado, para outra, em que a cidade é vista como um pólo cultural, social, económico e tecnológico moderno. Neste contexto de relação entre o marketing e os territórios inteligentes, existem factores que têm ganho proeminência e assumido diferentes formas no quadro desta conexão, como por exemplo, a educação, os recursos humanos qualificados, o capital intelectual e relacional, entre outros (Figura 7). Desta forma, é essencial pensar a cidade a nível da sua cultura, saúde, padrões de crescimento, atmosfera, necessidades de educação, identidade, qualidade de vida, entre outros, para que o marketing possa valorizar e promover a articulada distribuição e funcionalidade destas esferas urbanas.

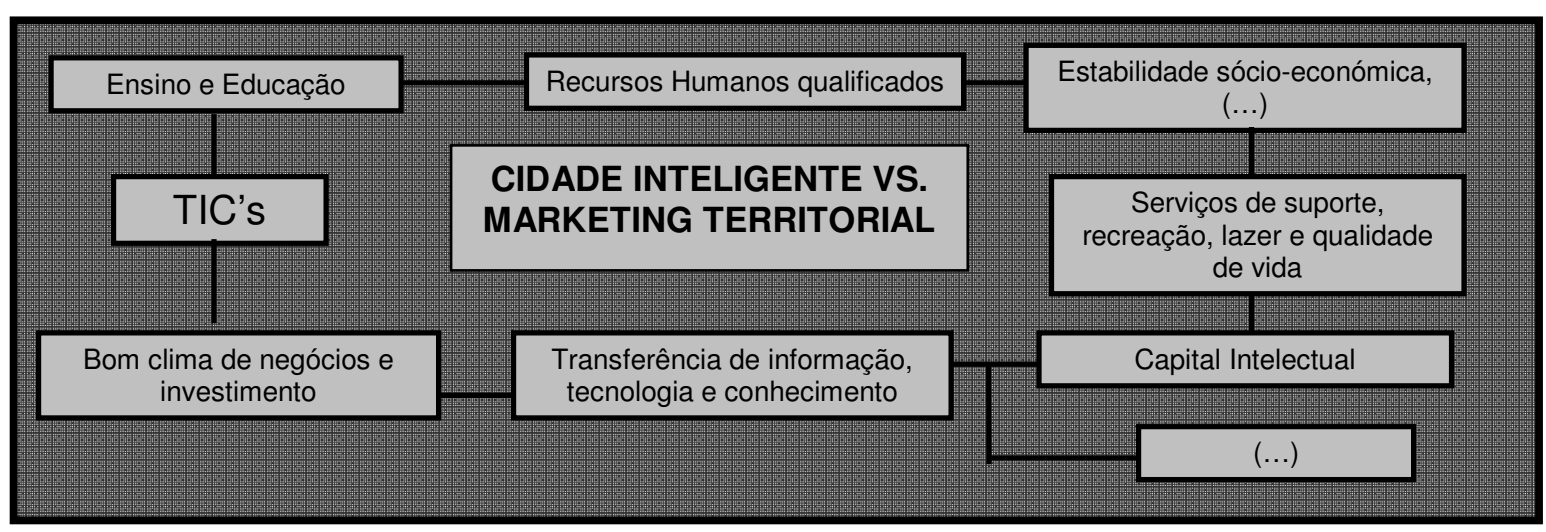

Figura 7. Factores de importância crescente no ambiente de relação entre o marketing territorial e a cidade inteligente 


\section{NOTAS FINAIS}

No campo teórico, nomeadamente na esfera de intervenção da Geografia, tem-se procurado reequacionar os territórios do conhecimento como estratégias de desenvolvimento e de marketing territorial de forma muito diversa, normalmente, através do recurso à importação e apropriação de saberes de outras áreas do conhecimento. Baseado nesta participação da Geografia e na perspectiva de que é importante que os territórios ganhem formas de emancipação sustentadas internamente e externamente por laços de relacionamento e condições únicas, as cidades são os pólos que, na maior parte das vezes, sintetizam os processos de desenvolvimento regional. A "inteligência" dos territórios, assente em indicadores educacionais, culturais, sociais e de acesso às tecnologias de informação e comunicação, independentemente de todos os factores negativos e positivos que apontamos até ao momento, pode, em nosso entender, potenciar a formação de territórios digitalmente inteligentes e inteligentemente digitais.

Ao nível do território e da visualização da cidade inteligente, torna-se imperativo que a este conceito se junte uma panóplia de políticas públicas territoriais de nova geração (SERRANO et al, 2005). No quadro da definição de uma cidade e região do conhecimento, deverão estar presentes políticas urbanas, de inovação, de investigação e de transferência de tecnologia, que permitam suportar e encaminhar processos de aprendizagem reflectidos territorialmente e assentes em três grandes esferas reguladoras: os componentes físicos, os componentes digitais e os componentes institucionais (Figura 8). O ponto de partida terá que residir nos indivíduos, nas empresas e nas organizações, que a partir de uma interligação e uso generalizado, difundirão estas dinâmicas para o território como um todo.

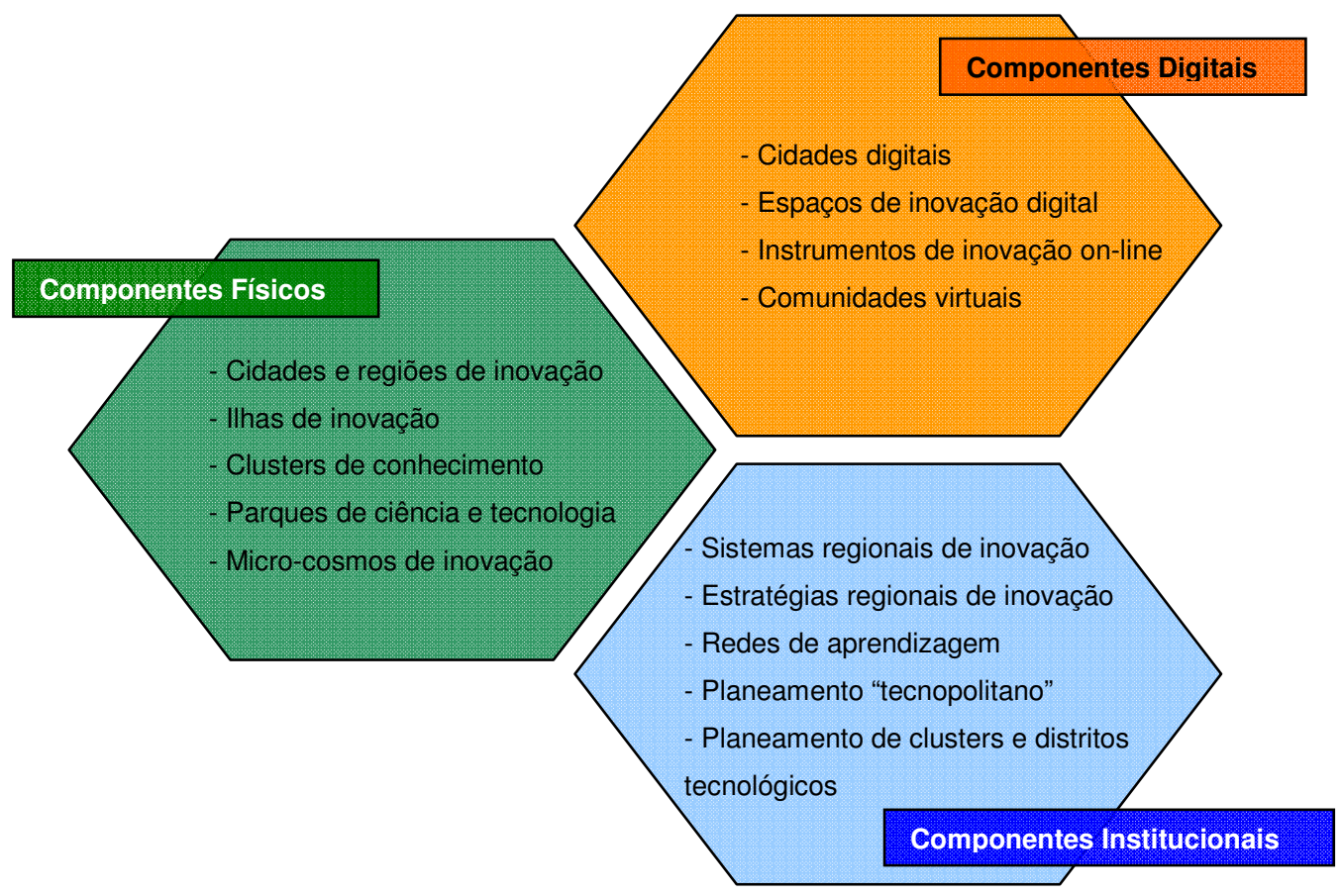

Figura 8. Componentes do território inteligente

Fonte: www.urenio.org/research.html 
Segundo os autores supracitados, para tornar estas estratégias exequíveis são necessários diferentes aspectos a nível territorial e de conhecimento. Segundo Teixeira (2003), as novas urbanidades baseadas no acesso aos canais de informação que tendem a concentrar num suporte digital as tarefas banais de relacionamento dos cidadãos com as instituições administrativas, financeiras e culturais, isto é, com a comunidade, criarão a separação entre os "tecnologicamente alfabetizados" e os "tecnologicamente analfabetos". Neste sentido, os que dispuserem de conhecimento e de ferramentas terão uma vantagem bastante representativa para beneficiar do ciberespaço (LÉVY, 2000), podendo promover a sua evolução enquanto indivíduos e comunidades inseridos num espaço urbano inteligente e global.

A cidade do futuro, na nossa opinião, deverá seguir o modelo da cidade inteligente, focada no conhecimento, na classe criativa e na tecnologia, incluindo todavia primordialmente uma valorização das pessoas e do território ao nível do capital intelectual e das especificidades dos processos de inovação, aprendizagem e conhecimento, do espaço, da sociedade e das economias. O inteligente surge, assim, como uma nova estratégia actual a diferentes escalas, sendo neste sentido fundamental analisarmos diferentes casos e escalas para percebermos totalmente o conceito de cidade inteligente. $O$ fundir dos ambientes real e virtual de inovação cria uma nova dimensão que marca o arranque das cidades inteligentes e o seu "alastrar" para as regiões.

Numa outra dimensão, desde o seu aparecimento a partir dos trabalhos de Wieviorka (1975) (cit. por KOTLER et al, 1999), o marketing territorial tem tido uma grande evolução sobretudo a partir dos anos 80 do século XX. A abertura e globalização da economia contribuíram para o disseminar dos espaços competitivos, inovadores e, mais recentemente, inteligentes, sendo que as cidades $e$ as regiões tiveram que se posicionar num novo quadro de competitividade. Deste modo, a valorização dos actores locais neste mundo global, obrigou à valorização do espaço e à formação da diferença. Assim, a especificidade territorial aparece como um trunfo, uma vantagem competitiva nesta sociedade em que as TIC's, o conhecimento e o desenvolvimento económico crescem exponencialmente, associando-se a uma crescente necessidade de interagir com os princípios do marketing. Desta forma, o marketing territorial tem-se convertido numa realidade da vida económica, política e social. Tem começado a alterar a representação espacial e tem influenciado a nossa percepção da realidade geográfica (BENKO, 2000: 9), económica, social e organizacional da cidade e da região.

A globalização através das novas tecnologias de informação e comunicação e a afirmação recente dos territórios do conhecimento levaram à emergência do marketing do lugar, com efeito territorializado nas imagens, representações, individualidade, especificidade e competitividade das cidades. Esta dinâmica e percepção distinguem diferentes lugares e cidades, criando novas especificidades territoriais e vantagens competitivas entre os espaços urbanos. A interpretação 
inovadora da identidade, da promoção das actividades culturais locais e das complexas e desafiadoras premissas têm contribuído para a expressão criativa da personalidade e individualidade dos lugares, cidades e regiões (MURRAY, 1993: 82). Ao mesmo tempo que a globalização aumentou o leque de escolhas referentes à localização de empresas, negócios e de habitação, verifica-se que as cidades passaram a não competir apenas na sua região ou país, mas no nível global, transformando o marketing territorial num conjunto de estratégias globais. Apesar da localização ter uma elevada importância nos dias de hoje, o marketing territorial tem que se basear nas redes de fluxos de informação entre cidades mundiais e recorrer às TIC's para se afirmar no contexto de um desenvolvimento integrado e de promoção da cidade do conhecimento. $\mathrm{Na}$ actualidade, a era da informação e do conhecimento é marcada pela criatividade, pelo capital intelectual e pela função do conhecimento e da inovação em espaço urbano, numa escala "glocal", em que o marketing assume uma vertente territorial pois define fronteiras, limites e localizações, valorizando, promovendo e atribuindo especificidades aos lugares, cidades e/ou regiões.

Em suma, neste quadro em que a nova economia, as TIC's e os territórios do conhecimento são cada vez mais reconhecidos, o marketing territorial tem que se afirmar de forma determinada, através de diferentes acções-chave que definam, de forma sustentada, o seu futuro. Neste sentido, torna-se necessário reforçar a integração, a participação comprometida no quadro da inovação, o fortalecimento de uma passagem do marketing do lugar para o desenvolvimento do lugar, reforçando uma mudança de mentalidade de base, a definição e utilização de novos instrumentos de promoção dos lugares, a reformulação e atribuição de novas competências e atributos aos seus profissionais, proporcionando-lhes uma visão mais alargada e mais adaptada às questões territoriais, e, por fim, a mudança de mentalidades no sentido de definir um novo conceito de espaço e lugar.

\section{REFERÊNCIAS BIBLIOGRÁFICAS}

- Amoêda, R. (2003) Cidades Digitais: Novas Modos de Habitar? Workshop Cidades e regiões Digitais, Impacto na Cidade e nas Pessoas. Universidade Fernando Pessoa, Porto.

- Antonelli, Cristiano e Ferrão, João (2001) Comunicação, conhecimento colectivo e inovação: as vantagens da aglomeração geográfica. Imprensa de Ciências Sociais, Lisboa.

- Asheim, B. (1995) Industrial districts and "learning regions". A condition for prosperity? Studies in Technology, Innovation and Economic Policy, Oslo.

- Benko, G. (2000) Estrategias de comunicación e marketing g urbano. EURE, Revista LatinoAmericana de Estudios Urbano Regionales, 26(79), 67-76.

- Cardoso, P., Gaio, S. e Abreu, J. (2003) Potencialidade das Cidades Digitais na Promoção do Turismo Urbano. Workshop Cidades e regiões Digitais, Impacto na Cidade e nas Pessoas. Universidade Fernando Pessoa, Porto.

- Castells, M. (2000) La Ciudad de la nueva economía. La Factoría, (12), Junio-Septiembre, sem paginação.

- Castells, M. (2002) A Sociedade em Rede. Fundação Calouste Gulbenkian, Lisboa

- Cidrais, A. (1998) O Marketing Territorial aplicado às Cidades Médias Portuguesas: os casos de Évora e Portalegre. Dissertação de Mestrado apresentada à Faculdade de Letras da Universidade de Lisboa, Lisboa. 
- Cooke, P. e Morgan, K. (1994) The Creative Milieu: A Regional Perspective on Innovation. In DOGSON e ROTHWELL (1994) The Handbook of Industrial Innovation. Edward Elgar, Londres.

- Cooke, P. (2002) Knowledge Economies: Clusters, Learning and Cooperative Advantage. Routledge, Londres.

- Ferrão, J. (1996) Educação, sociedade cognitiva e regiões inteligentes: uma articulação promissora. Inforgeo, 11, 97-104

- Firmino, R. e Camargo, A. (2005) Espaços Inteligentes, Cidades da Inteligência e Regiões Dinâmicas em Inovação: As Novas Tecnologias e a Configuração Urbana e Regional. Universidade de São Carlos, São Paulo.

- Florida, R. (1995) Towards the learning region. Futures, 27(5), 527-536.

- Furtado, G. (2003) Considerações sobre Planeamento e urbanismo face à Sociedade da Informação. Workshop Cidades e regiões Digitais, Impacto na Cidade e nas Pessoas. Universidade Fernando Pessoa, Porto

- Gama, Rui (1998) Sistemas de inovação, indústria e território: reflexões tendo por base os Centros Tecnológicos. Cadernos de Geografia, 17, 267-272.

- Gama, Rui; Cavaleiro, Célia; Figueiredo, Eduardo (1999) Novas Estratégias Empresariais no contexto da Economia Digital. Indústria Transformadora e Internet. Cadernos de Geografia, № especial, 29-38.

- Gama, Rui (2004) Dinâmicas Industriais, Inovação e Território. Abordagem geográfica a partir do Centro Litoral de Portugal. Fundação Calouste Gulbenkian, Coimbra.

- Gertler, Meric (2001) Spaces of Knowledge Flows: Clusters in a Global Context. Actas DRUID Summer Conference, 2729 Junho de 2005, Copenhagen.

- Gouveia, L. (2003) Cidades e Regiões Digitais: questões e desafios no digital. Workshop Cidades e regiões Digitais, Impacto na Cidade e nas Pessoas. Universidade Fernando Pessoa, Porto

- Gregersen, B.; Johnson, B. (1997) Learning Economies, Innovation Systems and European Integration. Regional Studies, 31(5), 479-490

- Guerreiro, E. (2002) Cidades Digitais - Tecnologia Social e Sociedade do Conhecimento. ECA, Universidade de São Paulo, São Paulo.

- Hudson, R. (1999) The Learning Economy, The Learning Firm and The Learning Region: A Symphatetic Critic of The Limits of Learning. European Urban and Regional Studies, 6(1), 59-71.

- Junqueiro, R. (2002) A idade do conhecimento: a nova era digital. Notícias Editora, Porto.

- Kearns, G. e Philo, C. (1993) Selling Places - the city as cultural capital past and present. Pergamon Press, Oxford.

- Komninos, Nicos (1992) Les nouveaux espaces de croissance. La naissance des centres du développement postfordiste. Espaces et Sociétés, 66-67, 217-233.

- Komninos, N. (2002) Intelligent cities: innovation, knowledge systems and digital spaces. Spon Press, Londres.

- Komninos, N. (2006) The architecture of intelligent cities. Integrating human, collective, and artificial intelligence to enhance knowledge and innovation. Actas da $2^{\text {nd }}$ International Conference on Intelligent Environments, Institution of Engineering and Technology, Atenas, 13-20.

- Kotler, P., Asplund, C., Rein, I. e Haider, D. (1999) Marketing Places Europe. Attracting Investments, Industries, Residents and Visitors to European Cities, Communities, Regions and Nations. Financial Times, Prentice Hall, Londres.

- Lévy, P. (1997) Cibercultura. Instituto Piaget, Lisboa.

- Lopes, V., O’Neill, H. e Machado, V. (2003) Cidades e Regiões Digitais: Uma viagem entre o Espaço Físico e o Espaço Digital. Workshop Cidades e regiões Digitais, Impacto na Cidade e nas Pessoas. Universidade Fernando Pessoa, Porto.

- Lundvall, Bengt-Ake (1995) National Systems of Innovation. Towards a Theory of Innovation and Interactive Learning. Pinter, Londres.

- Lundvall, B. (2000) The globalizing learning economy. Oxford University Press, Oxford.

- Maillat, D. (1996) Milieux innovateurs et dynamiques des systèmes territoriaux de production. Sociedade e Território, 23, 19-30

- Malecki, Edward (1991) Technology and Economic Development. The Dynamics of Local, Regional and National Change. Longman Scientific and Technical, Londres.

- Malmberg, A. e Maskell, P.(1999) Localized Learning and Regional Economic Development. European Urban and Regional Studies, 6(1), 5-8

- Maskell, Peter; Malmberg, Anders (1999) The Competitiveness of Firms and Regions: "Ubiquitification" and the importance of localized learning. European Urban and Regional Studies, 6(1), 9-25. 
- Méndez, Ricardo;Caravaca, Immaculada (1996) Organización Industrial y Territorio. Ed. Síntesis, Madrid.

- Metcalfe, J.S.; Ramlogan, R. (2005) Limits to the economy of knowledge and knowledge of the economy. Futures, 37(7), 655-674.

- Mitchell, W. (1999) City of bits: space, place, and the infobahn. MIT Press, Cambridge, Mass.

- Murray, C.(2001) Making sense of place. New approaches to place marketing. Comedia, Leicester.

- Noisette, P. e Vallérugo, F. (1996) Le marketing des villes. Les Éditions d'Organisation, Paris.

- Radovanovic, D. (2003) Intelligence \& Lund. What lessons Lund can learn in order to become na intelligent city. Tese de Mestrado apresentada à School of Economics and Mangement of Lund University. Lund University, Lund.

- Santos, D. (2000) Innovation and Territory. Which strategies to promote regional innovation systems in Portugal?. European Urban and Regional Studies, 7(2), 147-157.

- Sassen, S. (2001) The Global City: New York, London, Tokyo. Routledge, Nova lorque.

- Serrano, A., Gonçalves, F. e Neto, P. (2005) Cidades e Territórios do Conhecimento - Um novo referencial para a competitividade. Edições Sílabo, Lisboa.

- Short, John; KIM, Yeong-Hyun (1999) Globalization and the City. Prentice Hall, Londres.

- Simmie, J. (1997) Innovation, Networks and Learning Regions? Regional Policy and Development Series. Regional Studies Association, Londres

- Simmie, J.(1998) Reasons for the development of "Islands of Innovation": Evidence from Hertfordshire. Urban Studies, 35(8), 1261-1289.

- Simmie, J. e Lever, W. (2002) Introduction: The Knowledge-based city. Urban Studies, 39(5-6), 855-857

- Van Den Berg , L. e Braun, E. (1999) Urban Competitiveness, Marketing and The Need for Organising Capacity. Urban Studies, 36(5-6), 987-999

Xavier, Jorge (2004) O impacto das cidades digitais na sociedade da informação. Universidade de Aveiro, Aveiro.

- www.europa.eu.int/comm/eurostat (EUROSTAT)

- www.yorkshire-foward.com

- www.bcn.es

- www.newventuretools.net

- www.sciencecityyork.org.uk 